\title{
DETECTION OF ULTRA-WIDE-BAND IMPULSIVE NOISE IN A 400 KV AIR INSULATED ELECTRICITY SUBSTATION
}

\author{
Qingshan SHAN ${ }^{1}$ I A GLOVER ${ }^{1}$ R RUTHERFORD $^{2}$ S BHATTI $^{1}$ R ATKINSON $^{1}$ I E PORTUGUES $^{1}$ P J MOORE $^{1}$ \\ ${ }^{1}$ Department of Electronic and Electrical Engineering, University of Strathclyde - UK \\ ${ }^{2}$ Scottish Power, Energy, Networks \& Telecommunications - UK \\ qingshan.shan@eee.strath.ac.uk
}

\begin{abstract}
A measurement campaign has been carried out in $400 \mathrm{kV}$ air insulated electricity substation to characterise and model radio frequency impulsive noise with a view to assessing its impact on wireless network technologies. The relatively recent availability of new technologies such as WiFi, Bluetooth and Zigbee means that particular emphasis has been put on higher frequency bands (e.g. 2.4, $5 \mathrm{GHz}$ ) than have previously been investigated. A detection system to measure wideband noise over a spectrum extending up to $5.1 \mathrm{GHz}$ has been designed, implemented and deployed in a large electricity substation in central Scotland. Results based on a preliminary analysis of the recorded data are reported.
\end{abstract}

\section{INTRODUCTION}

A large amount of instrumentation and control equipment is scattered throughout the compounds and control rooms of electricity substations. Information and control signals for both normal and abnormal operation are traditionally connected, using cables or optical fibres, to a SCADA (Supervision, Control and Data Acquisition) system [1] and/or its successor UCA (Utilities Communication Architecture) system [2]. Ethernet local area network (LAN) implementations of such UCA/SCADA systems, which simplify the addition/reconfiguration of instrumentation and the coordination of protection systems, have been proposed and are already being evaluated [3]. Significant flexibility and cost advantages over a wired LAN infrastructure would be gained, however, if signals could be routed around electricity substation compounds wirelessly. Furthermore, wireless communication technologies hold out the prospect of 'hot-line', sensors that can be deployed on energized high-voltage (HV) equipment without the inconvenience and costs associated with bridging the system's primary insulation [4, 5]. Wireless LAN and Wireless Personal Area Network (PAN) technologies represent obvious opportunities to realize these advantages. Whilst the naturally occurring noise environment is relatively benign at Wireless LAN $(2.4,5 \mathrm{GHz})$ and Wireless PAN $(2.4 \mathrm{GHz})$ frequencies [6], the man-made noise environment within a substation compound is complex and hostile due to (i) partial discharge (PD) arising from imperfect insulation and (ii) sferic radiation arising from switching and fault transients (The term sferic usually relates to radiation from a lightening event but is used here as a shorthand for similar radiation arising from any large current transient). An investigation into the vulnerability of WLAN and WPAN technologies to impulsive noise in electricity transmission substations is currently in progress [7]. One of the primary objectives is the detection and investigation of PD in the microwave bands used by WLAN and WPAN technologies such as IEEE $802.11 \mathrm{a} / \mathrm{b} / \mathrm{g}$, IEEE 802.15 .4 and IEEE802.15.3. This requires investigation of the frequency spectrum up to $5 \mathrm{GHz}$.

PD is an electrical discharge that fails to fully bridge the space between a pair of electrodes. It can occur around an electrode in a gas (corona), within gas bubbles in a liquid or within the space created by voids in a solid. HV plant (transformers, switchgear, cables etc) is especially prone to $\mathrm{PD}$ if its insulation is damaged and/or as its insulation ages. If remedial action is not taken the insulation can be seriously compromised leading, ultimately, to catastrophic failure. Energy from PD processes can be radiated whenever spectral components arising from current pulse edges extend into the radio frequency (RF) region [8]. Although the character of PD appears to have some dependence on the size and geometry of plant components (e.g. insulating spacers, L-shaped buses, T-branch buses) damping typically appears to become significant somewhere between 100 $\mathrm{MHz}$ and $300 \mathrm{MHz}$ and increases with increasing frequency above this [9]. PD energy in the frequency range $0.5-1.2$ $\mathrm{GHz}$, however, is readily radiated from apertures formed, for example, by insulating spacers or bushings [13]. PD current pulses in strong insulators (e.g. $\mathrm{SF}_{6}$ ) can have risetimes as short as $50 \mathrm{ps}$ and may contain significant energy at frequencies up to $3 \mathrm{GHz}$ [10].

Several methods and systems for detection of very-highfrequency (VHF, up to $300 \mathrm{MHz}$ ) and ultra-high-frequency (UHF, up to $3 \mathrm{GHz}$ ) PD in GIS have been investigated [1012]. These are intrusive techniques, however, in which VHF or UHF couplers are mounted directly onto items of plant. A non-intrusive PD measurement system based on RF technology has been shown capable of detecting energy at frequencies up to $1.2 \mathrm{GHz}$ [13]. The authors are not aware, however, of any non-intrusive measurements of PD at frequencies up to $5 \mathrm{GHz}$.

In this paper we describe a system to monitor impulsive noise in the general electricity substation environment and present preliminary measurement results. 


\section{MEASUREMENT SYSTEM}

An impulsive noise detection system has been developed. The system consists of a low-band (LB) TEM half-horn antenna, a high-band (HB) TEM half-horn antenna, a diskcone antenna, a WLAN dual-band $(2.4 / 5 \mathrm{GHz})$ antenna, a high-bandwidth $(6 \mathrm{GHz})$ digital storage oscilloscope (DSO) and a 1 TB external hard drive disk (HDD). A block diagram of the measurement system is shown in Fig. 1. The system is shown deployed in a $400 \mathrm{kV}$ substation control room in Fig. 2.

The TEM half-horn was selected as the principal antenna type for the collection of data because of its excellent impulse response characteristics. Details of the TEM halfhorn design are reported in [14] but a summary is repeated here.

The LB horn is constructed from a triangular aluminum plate and a $122 \mathrm{~cm} \times 122 \mathrm{~cm}$ aluminum 'ground' plane. The width $(w)$ of the triangular plate at the aperture is $65.1 \mathrm{~cm}$, its length $(L)$ is $84 \mathrm{~cm}$ and its aperture height measured from the ground plane $(h)$ is $20.1 \mathrm{~cm}$. The antenna feed is a $50 \Omega$ SMA connector with its flange in electrical contact with the ground plane and its centre-conductor connected to the triangular plate apex. The amplitude response, measured with network analyzer, shows the $-3 \mathrm{~dB}$ bandwidth of a pair of identical horns (transmit and receive) to be $1.264 \mathrm{GHz}$ covering the frequency range $716 \mathrm{MHz}-1.98 \mathrm{GHz}$. The peak value of the amplitude response occurs at $1.068 \mathrm{GHz}$. The HB horn triangular flange is constructed from a PCB. The flange width $(w)$ at the aperture is $21.7 \mathrm{~cm}$ and its length $(L)$ is $28 \mathrm{~cm}$. The aperture height $(h)$ is $6.7 \mathrm{~cm}$. The feed structure and ground plane are identical to those of the LB horn. The $-3 \mathrm{~dB}$ bandwidth of a cascaded pair (transmit and receive) is $3.195 \mathrm{GHz}$ ( 1.905 to $5.1 \mathrm{GHz}$ ) and the amplitude response peak value occurs at $2.13 \mathrm{GHz}$.

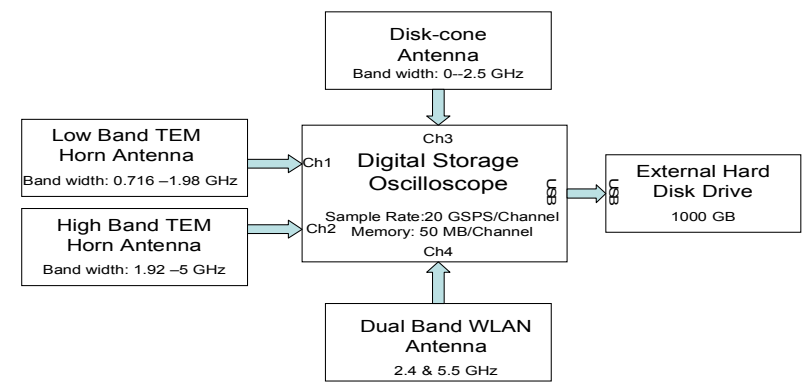

Fig. 1 Impulsive noise detection and recording system

The disk-cone antenna covers the frequency range below $710 \mathrm{MHz}$ which corresponds to the frequency range conventionally assumed to be important for PD. The details of this antenna design are reported in [13] but are, again, summarized below.

The disk-cone antenna consists of an inverted right circular cone over a circular 'ground' plane. The ground plane is
$171 \mathrm{~cm}$ in diameter and is constructed from aluminum plate. The cone was machined from solid aluminum. It has a base diameter of $13.3 \mathrm{~cm}$ and a height of $5.4 \mathrm{~cm}$. A non-inverted cone with equal base diameter sits on top of the inverted cone. The antenna is vertically polarized and has approximately flat frequency response in the range $0-2.5$ $\mathrm{GHz}$ with approximately constant $(50 \Omega)$ impedance.

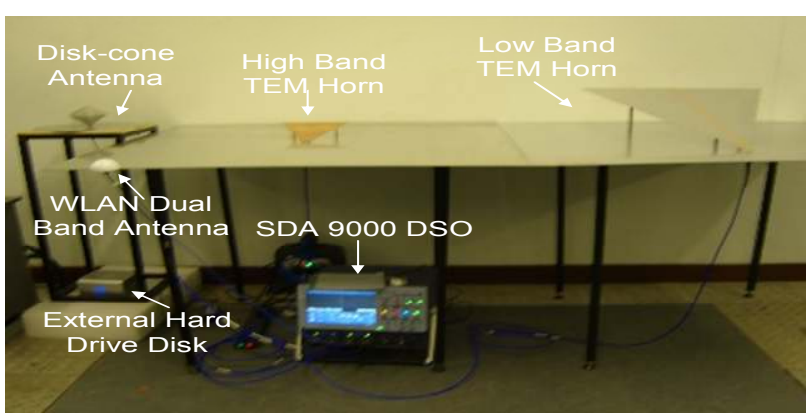

Fig. 2 Impulsive noise detection and recording system deployed in substation control room

A commercial dual-band WLAN antenna is also deployed. It has two passbands sufficiently wide to accommodate WLAN signals at 2.4 and $5 \mathrm{GHz}$.

The DSO is a LeCroy SDA 9000 with four simultaneous sampling channels. Each channel has a sampling rate of 20 GS/s and $50 \mathrm{MS}$ of RAM. The analogue bandwidth is 6 $\mathrm{GHz}$, and the input impedance $50 \Omega$.

The antennas are connected (directly) to the DSO. Direct sampling is used since previous studies, e.g. [15], have shown this to be advantageous in terms of minimising signal distortion. Interconnection is achieved via the use of 18 $\mathrm{GHz}, 50 \Omega$, coaxial cables. Time series are recorded using conventional amplitude triggering. Each recorded time series is $2.5 \mathrm{~ms}$ in length which is the longest possible using the available RAM. The recorded signals are saved to the external HDD which is connected with the DSO via a USB interface.

\section{MEASUREMENTS}

The measurement site is Strathaven air insulated substation in the UK, owned by Scottish Power Ltd. Fig. 3 is shows a composite image of the $400 \mathrm{kV}$ compound. The site also contains $275 \mathrm{kV}$ (out of shot behind the camera) and 132

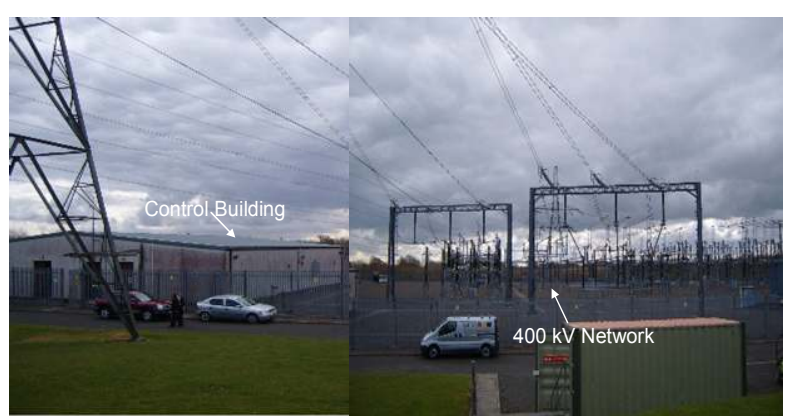

Fig. 3 Strathaven substation - $400 \mathrm{kV}$ compound 
$\mathrm{kV}$ compounds (out of shot to the left). The $400 \mathrm{kV}$ control building, in which the measurement system was deployed, is shown on the left in Fig. 3.

An example measured time-series instance obtained using the LB horn during the measurement campaign is shown in Fig. 4. The recorded signal has been divided into to five contiguous data segments (a) - (e). In each segment the abscissa is time in $\mu$ s and the ordinate is signal magnitude in $\mathrm{mV}$.

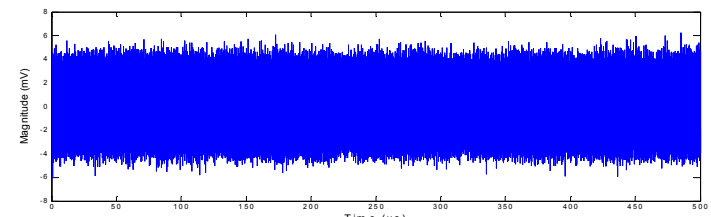

(a)

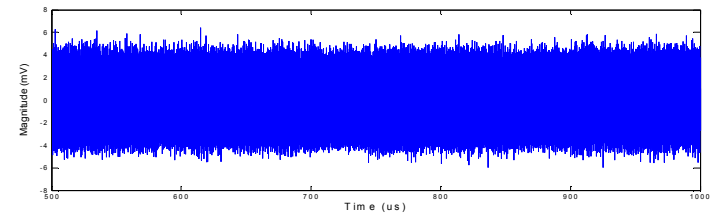

(b)

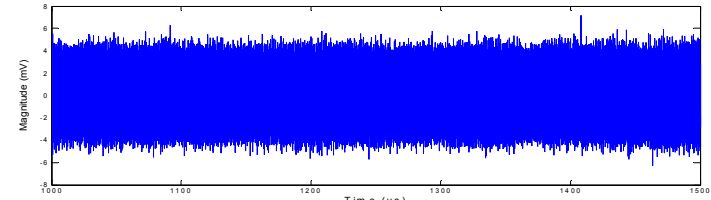

(c)

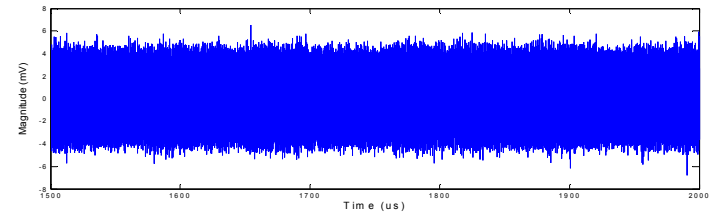

(d)

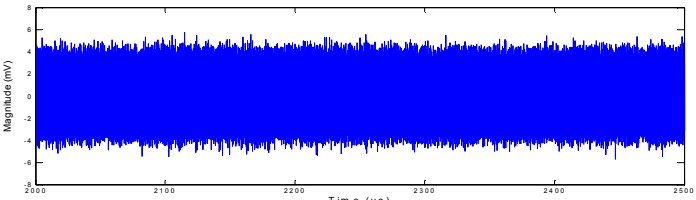

(e)

Fig.4. Original signal measured in power substation

\section{INTERFERENCE}

A spectral analysis of the measured data has been carried out, Fig. 5. Discrete spectral lines representing broadcast, radar, mobile communications and other radio signals are clearly visible in the frequency rang $0.5 \mathrm{MH}$ to $5 \mathrm{GHz}$. All these lines have been identified using, in part, OFCOM's radio frequency allocation table [16]. The most significant components are in the bands $0.5-1.2 \mathrm{MHz}, 90-108 \mathrm{MHz}$, $177-285 \mathrm{MHz}, 500 \mathrm{MHz}, 600-750 \mathrm{MHz}$, and at 833 $\mathrm{MHz}, 1.25 \mathrm{GHz}, 1.666 \mathrm{GHz}, 1.76 \mathrm{GHz}, 2.1 \mathrm{GHz}, 2.917$
$\mathrm{GHz}, 3.333 \mathrm{GHz}, 3.75 \mathrm{GHz}$ and $5 \mathrm{GHz} .0 .5-1.2 \mathrm{MHz}$ represents the MW AM broadcasting band. $90-108 \mathrm{MHz}$ is the FM radio band. 177 - $285 \mathrm{MHz}$ contains Public Access Mobile Radio (PAMR). The $500 \mathrm{MHz}, 600-750 \mathrm{MHz}$ and $833 \mathrm{MHz}$ are TV broadcasting bands. $1.25 \mathrm{GHz}$ is the civil airport radar band. $1.76 \mathrm{GHz}$ and $2.1 \mathrm{GHz}$ are the GSM 1800 and the $3 \mathrm{G}$ bands, respectively. $2.917 \mathrm{GHz}$ contains civil maritime, air traffic control and range safety radars. $3.333 \mathrm{GHz}$ is a maritime mobile band. $3.75 \mathrm{GHz}$ is C-Band

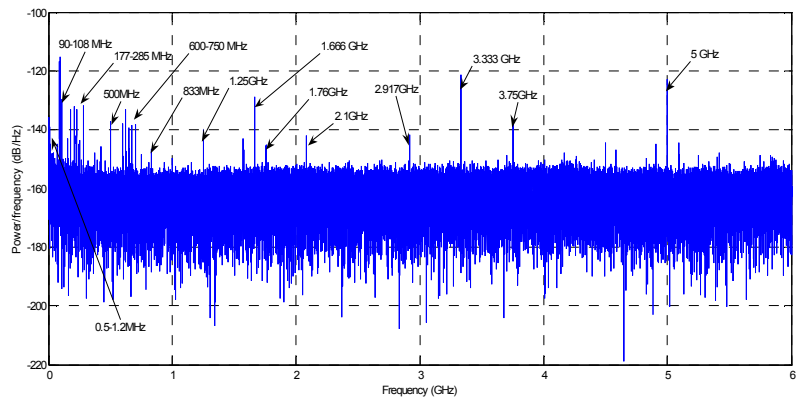

Fig.5. The spectrum of the measurement from $400 \mathrm{kV}$ power substation

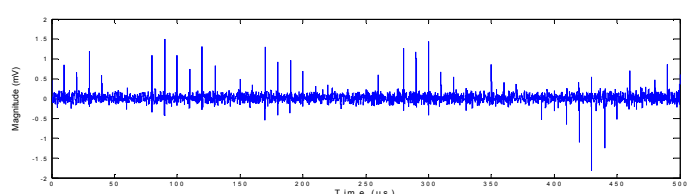

(a)

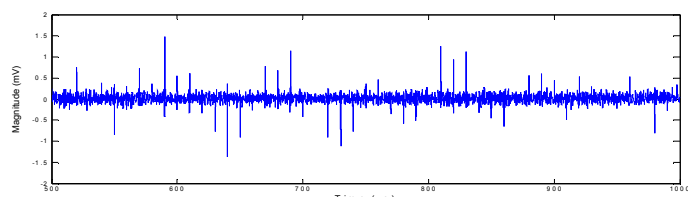

(b)

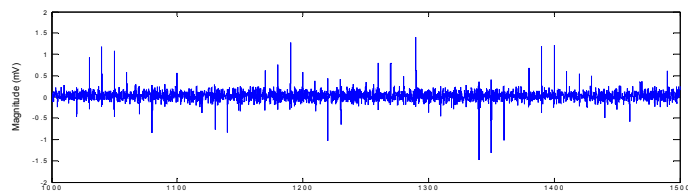

(c)

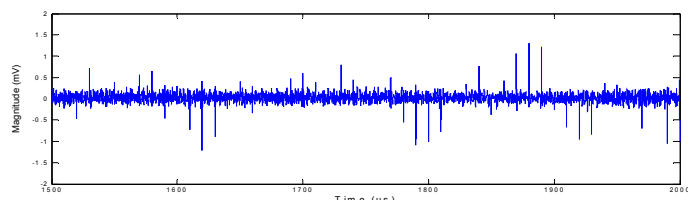

(d)

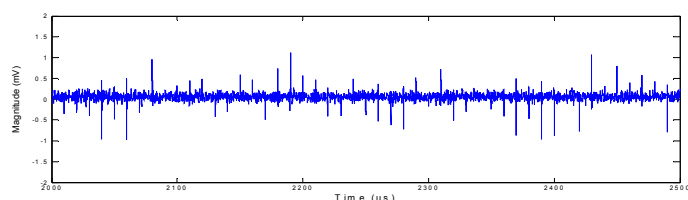

(e)

Fig.6. Impulsive noise 
satellite $\mathrm{TV}$ and $5 \mathrm{GHz}$ contains civil landing system signals. These broadcast, radar and communications signals obscure the impulsive noise processes that are the subject of this study. This is why there is no obvious sign of impulsive noise in Fig. 4.

\section{EXTRACTION OF IMPULSIVE PROCESS}

Since the impulsive noise is buried in coherent interference, the measured data are 'de-noised' using a wavelet transform based pre-processing techniques. The de-noising algorithm is described in [17]. Fig. 6(a) - (e) show the time series segments after pre-processing. The abscissa is time in $\mu \mathrm{s}$ and the ordinate is de-noised signal amplitude in $\mathrm{mV}$. An impulsive noise process is now clearly visible.

\section{CONCLUSION}

A measurement campaign to detect, and record, impulsive noise in an electricity substation in frequency bands hitherto ignored has been presented. The impulsive noise is weak due to the distance between the source and the measurement equipment and the impulsive process is thus obscured by strong, coherent, interference. The impulsive noise has been extracted using signal processing and its preliminary statistics obtained.

\section{ACKNOWLEDGMENTS}

The UK Engineering \& Physical Sciences Research Council (EPSRC) is gratefully acknowledged for financial support of this project under Grant EP/D049687/1.

\section{REFERENCES}

[1] IEEE Standard, "Definition, Specification, and Analysis of Systems Used for Supervisory Control, Data Acquisition, and Automatic Control," in IEEE Standard C37.1, 1994

[2] IEC Standard, "Communications Networks and Systems in Substations-Part1: Introduction and overview," in IEC Standard 61850-1, 2003.

[3] R. Ehlers, "Using UCA to integrate and deliver diagnostic data from substation," in 12th substation equipment diagnostics conference New Orleans, USA, 2004.

[4] H. G. Sedding, S. Bomben, S. Rizzeto, and R. Densley, "Assessment of station cable condition using wireless telemetry and diagnostic tests," in 2001 EEIC conference, 2001.

[5] P. Duggan, P. Dillilo, P. DiScala, R. Schwabe, J. Braun, N. Fujimoto, and S. Rizzetto, "Field experience with live wireless telemetry sensors on power equipment operating to $345 \mathrm{kV}$," in 12 th substation equipment diagnostics conference New Orleans, USA, 2004.

[6] "Radio noise," in ITU-R Recommendation, 2003, pp. 372-378.
[7] I. A. Glover, Q. Shan, P. J. Mooore, I. E. Portugues, and R. J. Watson "An investigation into the vulnerability of WLAN and WPAN technologies to impulsive noise in electricity transmission substations," in Ninth International Symposium on Communication Theory and Applications ISCTA'07, Ambleside, Lake District, UK, 2007.

[8] P. J. Moore, I. E. Portugues, and I. A. Glover, "Radiometric location of partial discharge sources on energized high-Voltage plant," Power Delivery, IEEE Transactions on, vol. 20, pp. 2264-2272, 2005.

[9] T. Sakakibara, H. Murase, E. Haginomori, S. Wakabayashi, K. Emoto, and A. Ogawa, "Study of propagation phenomena of partial discharge pulses in gas insulated substation," Power Delivery, IEEE Transactions on, vol. 13, pp. 768-776, 1998.

[10] M. D. Judd, O. Farish, J. S. Pearson, and B. F. Hampton, "Dielectric windows for UHF partial discharge detection," Dielectrics and Electrical Insulation, IEEE Transactions on [see also Electrical Insulation, IEEE Transactions on], vol. 8, pp. 953958, 2001.

[11] T. Huecker and J. Gorablenkov, "UHF partial discharge monitoring and expert system diagnosis," Power Delivery, IEEE Transactions on, vol. 13, pp. 1162-1167, 1998.

[12] R. Kurrer and K. Feser, "The application of ultra-highfrequency partial discharge measurements to gasinsulated substations," Power Delivery, IEEE Transactions on, vol. 13, pp. 777-782, 1998.

[13] P. J. Moore, I. Portugues, and I. A. Glover, "A nonintrusive partial discharge measurement system based on RF technology" in Power Engineering Society General Meeting, 2003, IEEE, 2003, p. 633 Vol. 2.

[14] Q. Shan, I. A. Glover, P. J. Moore, I. E. Portugues, M. Judd, R. Rutherford, and R. J. Watson, "TEM Horn Antenna for Detection of Impulsive Noise," in EMC Europe 2008, Hamburg, Germany, 2008.

[15] I. E. Portugues, P. J. Mooore, and I. A. Glover, "An investigation into the effect of receiver bandwidth for the interpretation of partial discharge impulses using remote radio sensing," in International University Power Engineering Conference, 2002, pp. 529-533.

[16] UK OFCOM, "United Kingdom table of radio frequency allocations $9 \mathrm{kHz}-105 \mathrm{GHz}$," Accessed on 07/07/2008 13:24, Available: http://www.ofcom.org.uk/static/archive/ra/publication/ ra info/ra365.htm.IEEE Criteria for Class IE Electric Systems (Standards style), IEEE Standard 308, 1969.

[17] Q. Shan, I. A. Glover, P. J. Moore, I. E. Portugues, Rutherford, and R. J. Watson, R Atkinson, Shahzad Bhatti, 2009, " De-noising impulsive noise measured in $400 \mathrm{kV}$ power substation ", International Energy and Environment Conference, Cambridge, UK. (In press) 